\title{
A GESTÃO DO SERVIÇO PÚBLICO E ABASTECIMENTO DE ÁGUA POTÁVEL NA REGIÃO METROPOLITANA DE BELÉM: O CASO DO MUNICÍPIO DE ANANINDEUA - PARÁ - BRASIL
}

\author{
Andreza Barbosa Trindade ${ }^{(a)}$, Michel Pacheco Guedes ${ }^{(b)}$, Carlos Alexandre Leão Bordalo ${ }^{\text {(c) }}$ \\ Natália Rodrigues das Graças Monteiro ${ }^{(d)}$ \\ (a) Discente e Bolsista da Faculdade Geografia e Cartografia, Universidade Federal do Pará, \\ and_trindade@yahoo.com.br \\ (b) Professor Pesquisador da Faculdade Geografia e Cartografia, PPGEO/ Universidade Federal do Pará \\ professormichelguedes@yahoo.com.br \\ ${ }^{(c)}$ Professor Pesquisador da Faculdade Geografia e Cartografia, PPGEO/ Universidade Federal do Pará \\ carlosbordalo@oi.com.br \\ (d) Discente e Bolsista da Faculdade Geografia e Cartografia, Universidade Federal do Pará \\ nataliarodrigues574@gmail.com
}

\section{EIXO: BACIAS HIDROGRÁFICAS E RECURSOS HÍDRICOS: ANÁLISE, PLANEJAMENTO E GESTÃO}

\begin{abstract}
O artigo apresenta o sistema/rede de abastecimento de água, fornecidas pela Companhia de Saneamento do Pará - COSANPA na Região Metropolitana de Belém, no município de AnanindeuaPA. Observando suas diferentes escalas gerenciais e áreas de abastecimento, identificando os melhores e os piores níveis de acesso e atendimentos à população desses serviços, utilizando alguns indicadores de abastecimento disponibilizados pelas bases de dados públicas e observações em campo. Os resultados contribuem para verificar as problemáticas que inferem na qualidade do sistema de abastecimento e atingem consequentemente a vida da população. Avaliamos pesquisas cartográficas, bibliográficas e documentais, incluindo informações dos instrumentos de gestão dos recursos hídricos, que servem de aporte técnico e teórico para esta investigação.
\end{abstract}

Palavras chave: abastecimento público de água, gestão dos recursos hídricos, região metropolitana de belém, ananindeua, geografia das águas.

\section{APRESENTAÇÃO}

Este artigo resulta do trabalho realizado pelo Grupo de Pesquisa Geografia das Águas da Amazônia - GGAM, situado à Faculdade de Geografia e Cartografia - FGC da Universidade Federal do Pará - UFPA, e é um produto parcial do projeto macro: "Distribuição Geográfica dos Serviços de Abastecimento de Água na Região Metropolitana de Belém - PA", sob coordenação do Professor Dr. Carlos Alexandre Leão Bordalo e atuação dos demais pesquisadores, discentes e professores desta UFPA com trabalhos vinculados ao Programa de Pós-Graduação em Geografia - PPGEO/UFPA.

Devido sua utilidade estratégica, a água é considerada um recurso: finito, em algumas regiões; escasso e de valor econômico, como instituiu no Brasil a Lei Federal n ${ }^{\circ}$ 9.433/1997 de acordo com a 
Política Nacional de Recursos Hídricos, sendo um elemento tão importante que sua disponibilidade e acesso definem o desenvolvimento que um país ou sociedade podem alcançar.

Para RIBEIRO (2012), a qualidade e potabilidade da água são tão importantes quanto sua disponibilidade, o autor nos diz ainda que o consumo de água contaminada pode provocar doenças e inclusive levar à morte. Estas são algumas das principais preocupações da Organização Mundial da Saúde - OMS que desde 1958 estabelece padrões internacionais para o consumo humano.

Embora a região amazônica esteja longe de uma "crise" de disponibilidade (quantidade) hídrica, a população das nossas metrópoles, principalmente os que residem nos bairros da zona de expansão da Região Metropolitana de Belém - RMB, têm sofrido com o atendimento insatisfatório da sua demanda por água, reforçando o que a geógrafa Bertha Becker nos fala de um grande paradoxo amazônida, de termos uma grande disponibilidade hídrica, confrontada com uma enorme inacessibilidade social .

Diante deste quadro é válido questionar se: Embora a região Amazônica seja farta de água, há dificuldade ao acesso nos municípios da RMB? Os índices de atendimento total, que indica a quantidade de água potável disponibilizada atende às necessidades da população? Os índices de atendimento estão dentro dos padrões estabelecidos pelos órgãos nacionais? Tais questões devem ser observadas para orientar a reflexões sobre o acesso a água que é bem público para grande parte da população e recurso hídrico para alguns interessados no lucro obtido pela sua comercialização

Para dar entendimento a essas questões investigamos por meios de dados secundários, e realizamos breve visita de campo para reconhecimento de parte das subestações de abastecimento de água dos municípios da RMB. Fizemos uma análise dos modelos de administração dos serviços de distribuição e abastecimento público de água potável que são responsabilidade da Companhia de Saneamento do Estado do Pará - COSANPA à população da RMB frisando os índices do município de Ananindeua.

Obtivemos resultados a partir da consulta nos bancos de dados de acesso público e aberto nos sítios do banco de dados do Sistema Nacional de Informações sobre Saneamento - SNIS/Ministério das Cidades (2006/2015); do Plano Diretor do Sistema de Abastecimento de Água (PDSAA) da Região Metropolitana de Belém (RMB). Também obtivemos informações a partir dos documentos técnicos como; último Censo - Instituto Brasileiro de Geografia e Estatística - IBGE (2010), Atlas Brasil: Abastecimento Urbano de Água (2010) - Agência Nacional das Águas - ANA, O Plano Nacional de Recursos Hídricos PNRH (2003/2006) e A Pesquisa Nacional de Saneamento Básico - PNSB (IBGE/2008).

Dentre os elementos disponibilizados para avaliação tratamos dos índices de abastecimento total de água para os municípios que compõem a Região Metropolitana de Belém (RMB), e neste trabalho, 
damos ênfase ao município de Ananindeua, que obteve níveis de abastecimento público de água muito abaixo das médias nacionais. A extensa abordagem foi necessária para dar entendimento à pesquisa e à compreensão da organização das diferentes escalas gerenciais das águas, verificando as ações planejadas para o gerenciamento do abastecimento de água potável nas esferas estadual e municipal e se estas podem ou não chegar com níveis consideráveis no abastecimento aos municípios.

A oferta de água potável em quantidade suficiente para o abastecimento está prevista para as políticas públicas urbanas nas esferas nacional, estadual e municipal, compondo a Política Nacional de Saneamento Básico, incluindo os serviços de: abastecimento de água, esgotamento sanitário, limpeza urbana, manejo de resíduos sólidos, drenagem e manejo de águas pluviais urbanas, a Lei ${ }^{\circ} 11.445 / 07$ estabelece as diretrizes para o saneamento básico em todo o país que deve ser gerida a fim de promover saúde à população e a qualidade ao ambiente.

Quando qualificamos e representando espacialmente os dados brutos sobre abastecimento, podemos gerar informações que servem de ferramentas para melhor avaliar a gestão pública, suas áreas de atuação e as diferentes esferas do planejamento territorial urbano ambiental, bem como verificar se houve expansão na prestação desses serviços nas cidades; apontando em muitos casos a distribuição desigual. Os dados sobre abastecimento público de água quando combinados a outros indicadores, são informações valiosas para observar qualitativamente a oferta e principalmente verificar as condições de vida daqueles que têm direito de usufruírem dos serviços públicos e à água com qualidade, e que na realidade são atingidos pela problemática da inacessibilidade ao recurso hídrico, que lhes é cobrado, porém não lhes é fornecido de maneira adequada.

Nosso objetivo é através dos conceitos, teorias e métodos da geografia, apresentar a distribuição geográfica da rede/sistema de abastecimento de água fornecida pela Companhia de Saneamento do Pará COSANPA e demais prestadoras na RMB, com recorte à escala do município, onde Ananindeua é elencado para investigação.

\section{O LOCUS DA PESQUISA: O MUNCÍPIO DE ANANINDEUA}

Ananindeua é integrante do conjunto de sete municípios que compõem a Região Metropolitana de Belém (RMB), e foi criado pela Lei Complementar Federal no 14, de junho, em 1973. Em 2010 a população total da RMB era de 2.275.032 habitantes IBGE/CENSO (2010), e composta por seis municípios: Belém, Ananindeua, Marituba, Benevides, Santa Bárbara do Pará e Santa Isabel do Pará, e a partir de 2011 também por Castanhal. 


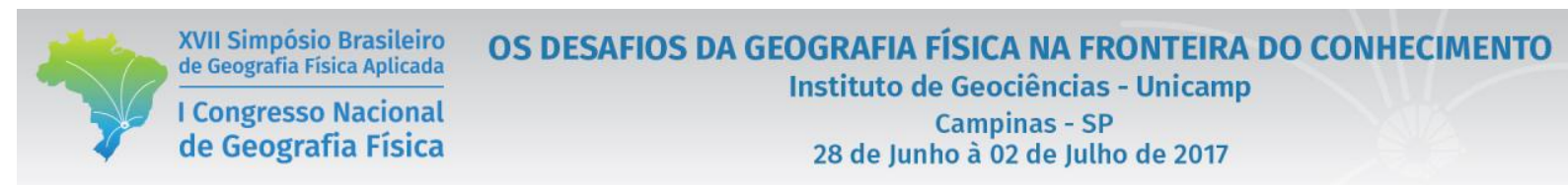

Ananindeua é o segundo maior município em termos populacionais do Estado do Pará com 470.819 habitantes, sendo $99,75 \%$ de população urbana, e 0,25\% de população rural, e uma densidade demográfica na ordem de: $2.477,56 \mathrm{hab} . / \mathrm{km}^{2}$. (IBGE, 2010). A sede do município detém as seguintes coordenadas geográficas: $1^{\circ} 23^{\prime} 00^{\prime \prime}$ de latitude sul e $48^{\circ} 24^{\prime} 00^{\prime}$ ' de longitude W. Gr. O município fica entre as coordenadas de $1^{\circ} 10^{\prime}$ e $1^{\circ} 30^{\prime}$ de latitude sul e $48^{\circ} 10^{\prime}$ e $48^{\circ} 30^{\prime}$ de longitude W. Gr. Sua altitude média é de $17 \mathrm{~m}$ acima do nível do mar (altitude da sede: $25 \mathrm{~m}$ ), na área da prefeitura municipal.

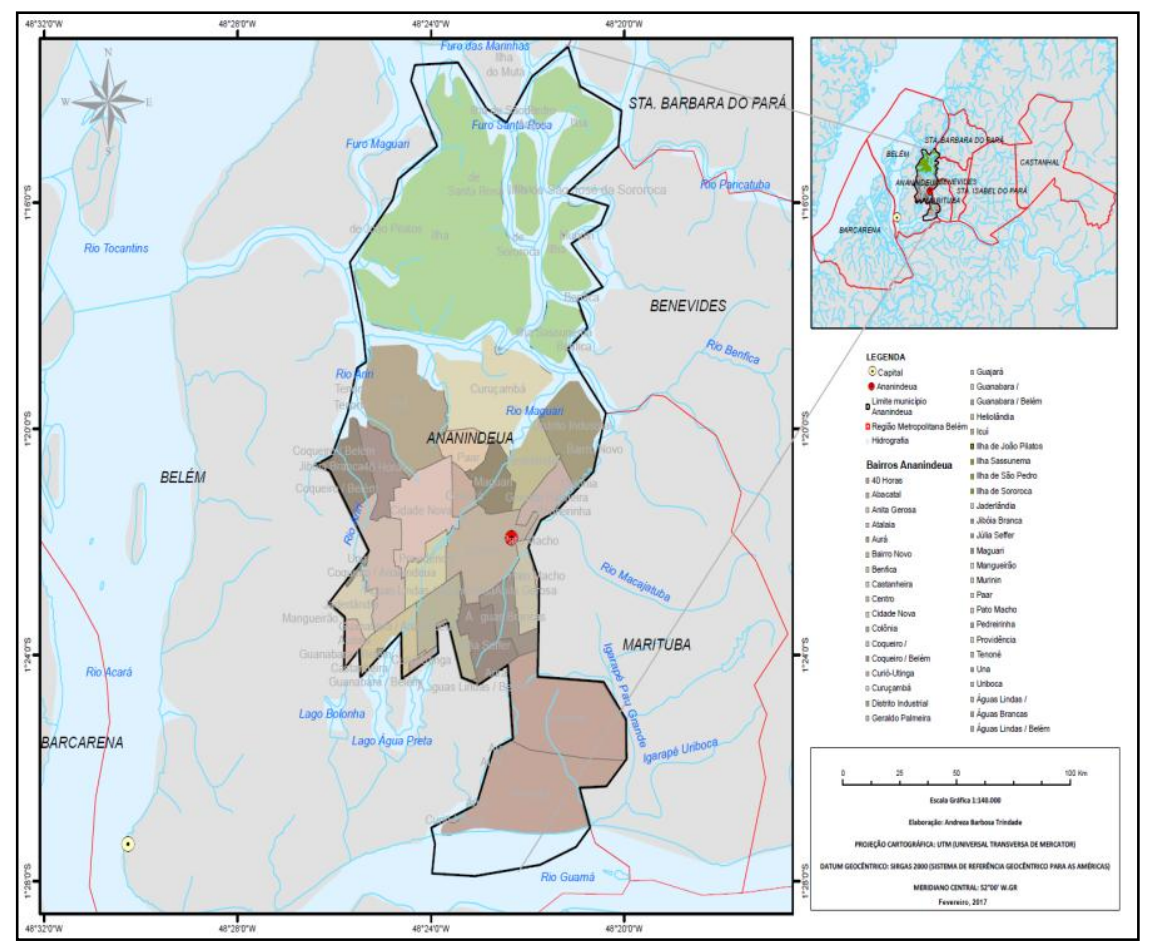

Figura 1. MAPA DE LOCALIZAÇÃO MUNICÍPIO DE ANANINDEUA

A sede municipal de Ananindeua ocupa atualmente uma área de 190,451 km² (IBGE, 2010) e está a 28 km de Belém pela BR-316. Essa rodovia federal, em conexão com a BR-010 (Belém-Brasília), coloca Ananindeua em acesso rodoviário a leste e ao sul do estado, através também da malha rodoviária estadual à essas regiões. Em Ananindeua, no ano 2000, as moradias populares se concentravam em partes dos bairros Icuí-Guajará, PAAR, 40 Horas e parte do Centro Administrativo no sentido norte do município, assim como os bairros do Sul: Santana do Aurá e o município de Marituba.

Apresentando dados do Censo 2010, 59,3\% da população residente nas regiões metropolitanas de São Paulo, Rio de Janeiro, Belém, Salvador e de Recife estão em aglomerados subnormais, sendo que a RMB é a região metropolitana brasileira com maior proporção de domicílios em aglomerados subnormais $(52,5 \%)$ e maior proporção de população residente em aglomerados subnormais entre as RMs e RIDEs do país $(53,9 \%)$, estando concentrada no município-sede, Belém, com 66\% do total (Observatório das 
XVII Simpósio Brasileiro

de Geografia Fisica Aplicada

I Congresso Nacional

de Geografia Física
OS DESAFIOS DA GEOGRAFIA FÍSICA NA FRONTEIRA DO CONHECIMENTO

Instituto de Geociências - Unicamp

Campinas - SP

28 de Junho à 02 de Julho de 2017

Metrópoles/IBGE, 2011). Do ponto de vista da gestão BORDALO (2006), aponta e questiona as constantes interrupções e que fatores estariam comprometendo a qualidade do sistema de abastecimento de água da Região Metropolitana de Belém.

\section{GESTÃO E GERENCIAMENTO DE RECURSOS HÍDRICOS}

De acordo com Lanna (2007), há uma diferenciação entre gerenciamento e gestão de recursos hídricos ou "gestão das águas"”. Para Lanna "A gestão é considerada de forma mais ampla, obrigando todas as atividades, incluindo o gerenciamento. Este é considerado uma atividade do governo”. pg. 745. A lei 9.433/97 institui a Política Nacional de Recursos Hídricos que é o “conjunto consistente de princípios doutrinários que conformam as aspirações sociais e ou governamentais no que concerne à regulamentação ou modificação nos usos, controle e proteção dos recursos hídricos”. pg 744. (Lanna, 2007).

Setti (2001) compreende Gestão de Recursos Hídricos como "a forma pela qual se pretende equacionar e resolver as questões de escassez relativa dos Recursos Hídricos, bem como, fazer uso adequado, visando a otimização dos recursos em benefício da sociedade”. (pg.10). Entende-se Gerenciamento de Recursos Hídricos, como o "conjunto de ações governamentais destinadas a regular o uso e o controle dos recursos hídricos e avaliar a conformidade da situação corrente com os princípios doutrinários estabelecidos pela política das Águas" (Setti, 2001).

Essa estrutura organizacional é observada no âmbito estadual, quando verificamos as diferentes esferas e escalas governamentais (municipal e estadual, pública e privada) atuando sobre um mesmo território na RMB, e ainda quando há privatizações no setor de abastecimento de água em alguns municípios como Barcarena-PA, que tem seu serviço de água e esgoto concedido à uma empresa privada por um período de trinta anos. A AEGEA - Águas de São Francisco Saneamento, Holding de saneamento que atua em todo o Brasil, e atuando no município desde 2014. Diante da afirmação de Setti, (2001) o serviço irá conflitar no que se refere às esferas governamentais (agora pública e privada), implicando nas escalas gerenciais estadual e municipal das águas, para exemplificar.

Assim sendo o abastecimento de água é um serviço presente nas políticas de saneamento básico, e compõe o gerenciamento de recursos hídricos, esta abordagem conta com amplas e relevantes investigações nas diversas áreas de conhecimento. Nossa pesquisa dá enfoque para uma leitura geográfica a cerca da gestão e gerenciamento do abastecimento publico de água, atendendo também as demais áreas de interesse, questionamos o papel do Estado e os investimentos governamentais realizados para a gestão e implementação de ações voltadas ao tema. 


\section{A AÇÃO DA COMPANHIA DE SANEAMENTO DO ESTADO DO PARÁ - COSANPA NA} RMB.

A Companhia de saneamento do estado do Pará é uma sociedade de economia mista com administração pública, e tem abrangência regional. Segundo dados do Atlas Brasil-Abastecimento Urbano de Água/2010 há comprometimento em boa parte dos mananciais urbanos de abastecimento de água, onde grande parte da população de Capitais como Belém, Brasília e São Paulo há tempos sofrem com o racionamento de água potável fornecido pelas companhias públicas. Esse problema do abastecimento de água vivido na Região metropolitana de Belém é realidade também das Regiões Metropolitanas (RMs) e Regiões Integradas de Desenvolvimento Econômico (RIDEs) brasileiras.

Desde o começo do século XX dois modelos de gestão dos serviços de saneamento, foram implementados progressivamente nos países de periferia capitalista, a saber: "privados não regulamentados" e "serviços de controle público", CASTRO, (2005). No Brasil, houve crescente intervenção estatal no setor, a partir de 1960, com a criação das Companhias Estatais de Saneamento Básico - CESB e sua consolidação via Plano Nacional de Saneamento - PLANASA em 1971. A gestão desses serviços pela via pública, no caso das CESB, foi instituída distante dos mecanismos de controle sociais democráticos, da ditadura militar, como bem discorre CASTRO, (2005):

\footnotetext{
"Essa cultura autoritária se refletiu, por exemplo, no fato de que as "concessões" municipais às empresas estatais na década de 1970, muitas delas ainda vigentes, praticamente não outorgaram direitos ao poder concedente, o município e muito menos aos cidadãos comuns individuais, na qualidade de usuários." (pg. 53).
}

Na Região Metropolitana de Belém a COSANPA realiza o abastecimento público com água captada superficialmente, proveniente do sistema de captação do manancial do Utinga, onde ocorre a captação de água no rio Guamá e bombeamento para os lagos, Água Preta e Bolonha, seguindo destes para as estações de tratamento de água - ETAs - do Bolonha, e dos bairros de São Brás e Marco.

Após o tratamento a água é distribuída para os reservatórios e estações elevatórias de nove setores de distribuição de água da zona central de Belém (RIBEIRO, 2004; BORDALO, 2006).

O Lago Água Preta armazena em torno de $10.555 .000 \mathrm{~m}^{3}$ de água bruta que recebe diariamente via adutoras do Rio Guamá, proveniente das chuvas e das nascentes do Igarapé Água Preta, estando conectados através de um canal artificial, ao Lago Bolonha que armazena $2.100 .000 \mathrm{~m}^{3}$. Outra fonte de abastecimento provém dos mananciais subterrâneos, nestes a captação é realizada através da perfuração de poços com capacidades que variam de 60 a $360 \mathrm{~m}^{3} / \mathrm{h}$. Estas fontes subterrâneas são comuns na região amazônica, sendo utilizadas desde o período colonial, através da perfuração de poços públicos para o uso da população, onde hoje o tratamento é inexistente, segundo Ponte (PONTE, 2003). 


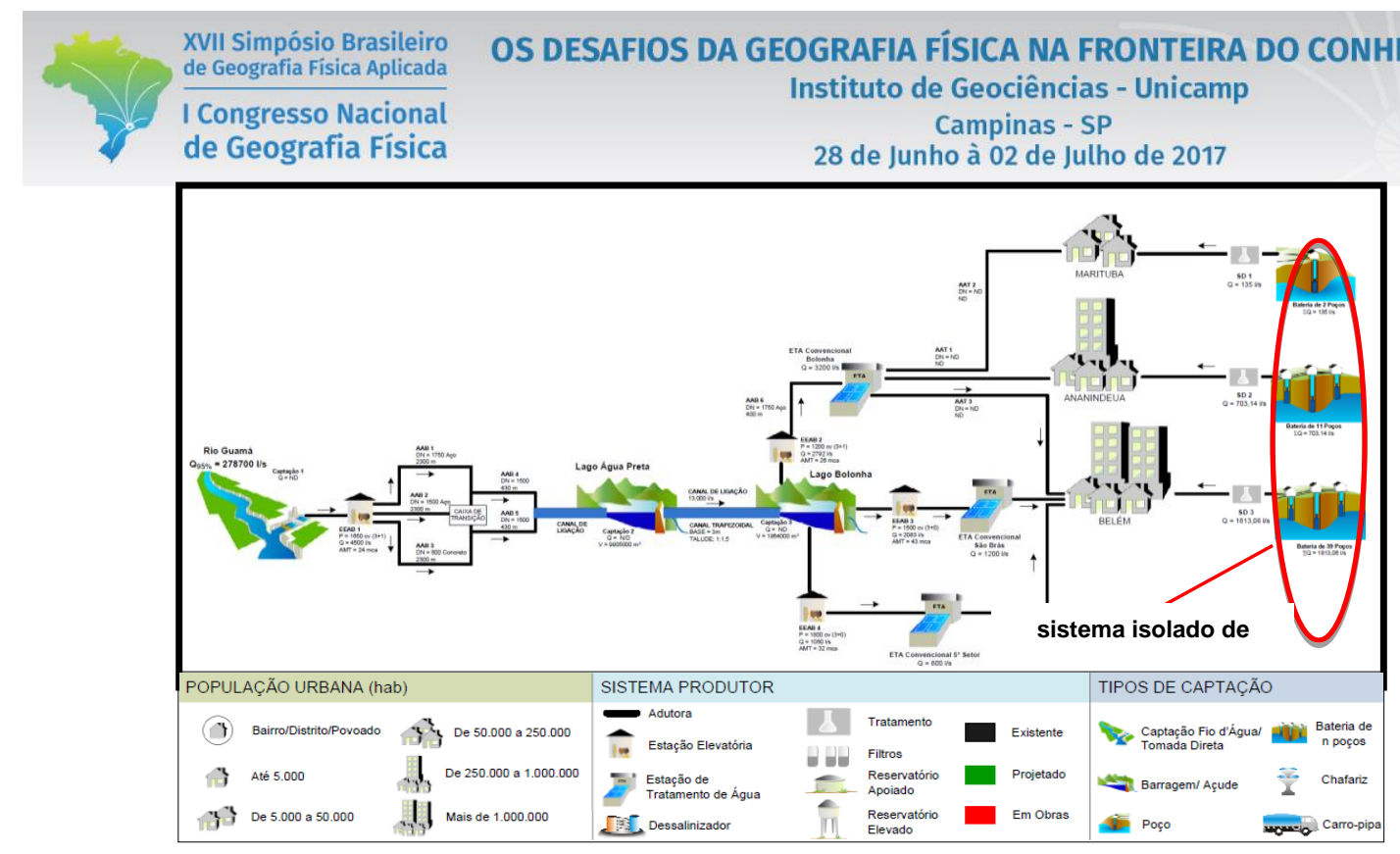

Figura 2. SISTEMA INTEGRADO BOLONHA-UTINGA

Fonte: Atlas de Saneamento Básico - ANA, 2009 (adaptado)

O sistema de Abastecimento de água e esgotamento sanitário do município de Belém em parte atende o município de Ananindeua. Está disposto em duas grandes zonas de abastecimento zona central e de expansão. Em termos de divisão física está disposta em 39 setores sendo nove na zona central (bairros) e 30 na zona de expansão, compreendido por bairros afastados do centro além dos municípios de Ananindeua e Marituba. Observando que os 9 setores inseridos da zona central estão localizados exclusivamente no município de Belém (PMSB, 2014).

O volume de perdas no sistema da RMB também tem altos índices. Segundo LEÃO, ALENCAR e VERÍSSIMO (2008), este volume ultrapassa a marca de 55 milhões de $\mathrm{m}^{3}$. Este volume perdido, segundo os mesmos autores, seria suficiente para abastecer 1,5 milhão de pessoas durante um ano, considerando-se um consumo médio de 100 litros dia/habitante. Esta situação contrapõe-se às metas do Brasil de atender $83 \%$ da população até 2015 , sendo necessário um crescimento de $18 \%$ do atendimento para que se alcançá-la.

Esse quadro de perdas é confirmado pelo engenheiro Fernando Martins, diretor de mercado da Cosanpa, que em entrevista declarou que "cerca de $45 \%$ da água captada e tratada pela Companhia é desperdiçada. Entre cinco pessoas, o consumo acima de 20 mil litros de água, por mês, pode representar desperdício" (ASCOM/COSANPA, 28 de junho de 2011).

Atualmente a COSANPA sofre pressões no que se refere ao seu processo de privatização que segue em andamento, aja vista os indicadores críticos que foram apontados abaixo das médias nacionais. Como já é noticiado publicamente nas diversas mídias desde o ano 2016 (fig. 15), o Banco Nacional do Desenvolvimento - BNDES é o condutor do processo de concessões e outras formas de desestatização de 
ativos do Programa de Parcerias para Investimentos (PPI) do governo, no presente liderado pelo o chefe do poder executivo Federal o Sr. Michel Miguel Elias Temer Lulia. O Banco se caracteriza também como um instrumento do Governo Federal para o financiamento de longo prazo e investimento em todos os segmentos da economia brasileira.

Como informa o próprio BNDES, (2017) haverá atuação na estruturação de projetos que visem atrair a parceria privada, identificando oportunidades e conduzindo o processo desde a fase de estudos e modelagem, até a assinatura do contrato de concessão entre os governos estaduais e as concessionárias.

Cabe também ao banco, no papel de membro do Conselho do PPI, indicar empreendimentos que se qualifiquem para sua implementação por meio de parcerias privadas.

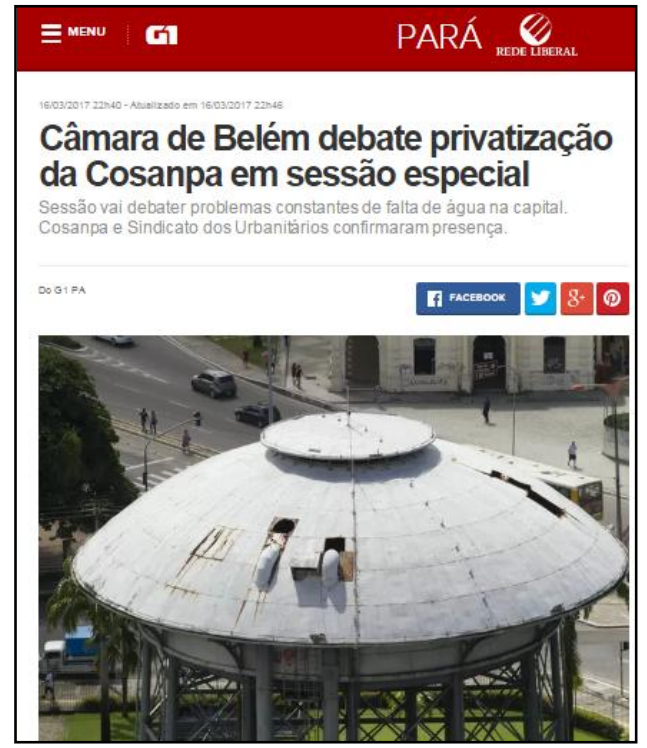

Fonte: G1/Pará 2017. Foto: Shirley Penforte/Amazônia Jornal)

FIGURA 3. DEBATE SOBRE PRIVATIZAÇÃO DA COSANPA

\section{RESULTADOS}

O sistema produtor de água que abastece o município de Ananindeua (ver quadro 1.) é composto por abastecimento de água advindo de manancial subterrâneo e superficial, atendido por um dos setores integrados que atendem cerca de $60 \%$ da população da RMB.

\begin{tabular}{|c|c|c|c|}
\hline MUNICIPIO & ORGÄO OPERADOR SERVIÇOS DE AGUA E ESGOTO & COMPETENCIA & CAPTAÇÄO \\
\hline Castanhal & COSANPA & ESTADUAL & SUBTERRANEA \\
\hline Benevides & SEMINFRA - Benevides & MUNICIPAL & SUBTERRANEA \\
\hline Santa Bárbara do Pará & Prefeitura Municipal de Santa Bárbara do Pará. & MUNICIPAL & SUBTERRANEA \\
\hline Santa Isabel do Pará & Secretaria Municipal de Infraestrutura e Obras Públicas & MUNICIPAL & SUBTERRANEA \\
\hline Belém & COSANPA/SAAEB* & ESTADUAL/MUNICIPAL & $\begin{array}{c}\text { SUPERFICIAL/ } \\
\text { SUBTERRANEA }\end{array}$ \\
\hline Ananindeua & COSANPA/SESAN - Ananindeua & ESTADUAL/MUNICIPAL & $\begin{array}{c}\text { SUPERFICIAL } \\
\text { SUBTERRANEA }\end{array}$ \\
\hline Marituba & COSANPA/SEHAB - Marituba & ESTADUAL/MUNICIPAL & $\begin{array}{c}\text { SUPERFICIAL/ } \\
\text { SUBTERRANEA }\end{array}$ \\
\hline
\end{tabular}

* serviço incorporado à COSANPA em 2014, resolução n n 001/201 de 08 de julho/2014. 


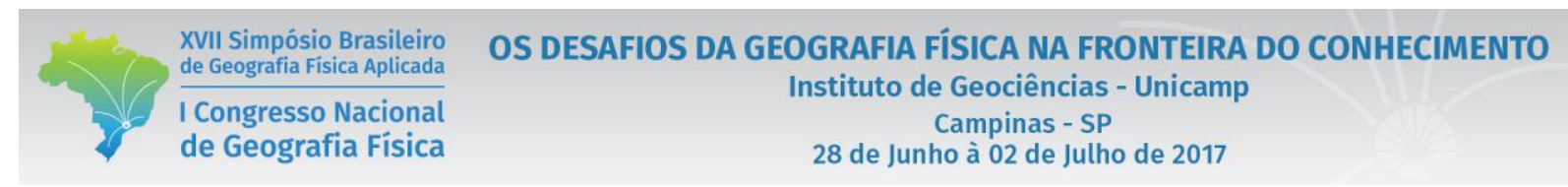

O ritmo da expansão urbana e a crescente demanda por água encanada é notada desde os anos 1990, como bem aponta BORDALO, 2006. (pg. 152-153). Esse ritmo colabora com o abismo entre expansão populacional na RMB e as deficientes ações de expansão do sistema de abastecimento de água fornecido pela COSANPA. No que se refere ao município de Ananindeua observamos que o mesmo pertence à zona de expansão com relação ao crescimento urbano em direção à BR 316, que é abastecida por 68 setores, concentrados no município de Ananindeua e Marituba 27 desses. Ver quadro 2.

\begin{tabular}{|c|c|c|c|}
\hline № Setores & Zona d & imento & Municipio \\
\hline 10 & Central & Central & \multirow{6}{*}{ Belém } \\
\hline 9 & Aeroporto & \multirow{8}{*}{ Expansão } & \\
\hline 6 & Augusto Montenegro & & \\
\hline 9 & Icoaraci & & \\
\hline 5 & Outeiro & & \\
\hline 5 & Mosqueiro & & \\
\hline 27 & BR-316 & & Ananindeua e Marituba \\
\hline 4 & Benevides & & Benevides \\
\hline 3 & Santa Barbara & & Santa Bárbara \\
\hline 78 & TOTAL & & \\
\hline
\end{tabular}

Elaboração: TRINDADE, A. B. Fonte: COSANPA, 2006.

\section{QUADRO 2. ZONAS DE ABASTECIMENTO CENTRAL E DE EXPANSÃO}

Prosseguindo os resultados, Segundo pesquisa realizada pelo instituto Trata Brasil 2016, baseada em dados do SNIS/2014/206 considerando os cem maiores municípios do Brasil em termos de população, aqueles que apresentaram os vinte melhores e os dez piores índices de saneamento. Para tanto consideramos o índice de abastecimento total de água. Para analisar os dez piores, o instituto utilizou indicadores de atendimento de água, coleta e tratamento de esgotos, índice de perdas e investimentos no período 2010-2014.

Nesta pesquisa Ananindeua apareceu como o último colocado entre os dez piores, em dois períodos consecutivos da pesquisa, no que se refere somente ao indicador "abastecimento de água" com índice equivalente a $26,9 \%$ no atendimento total. Ressaltando que de todos os municípios ranqueados com os piores índices cinco estão na região Norte e dois no estado do Pará no na pesquisa de 2014, já para os resultados de 2016, Belém não consta entre as dez piores, permanecendo Ananindeua e Santarém. (tabelas 2 e 3). 


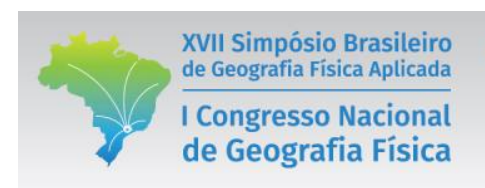

\begin{tabular}{|c|l|c|c|}
\hline Colocação & \multicolumn{1}{|c|}{ Municipio } & UF & Atendimento \\
\hline 91 & Petrolina & PE & $76,30 \%$ \\
\hline 92 & Belém & PA & $72,63 \%$ \\
\hline 93 & Gravatai & RS & $71,99 \%$ \\
\hline 94 & Caucaia & CE & $69,28 \%$ \\
\hline 95 & Aparecida de Goiânia & GO & $65,57 \%$ \\
\hline 96 & Jaboatão dos Guararapes & PE & $55,29 \%$ \\
\hline 97 & Santarém & PA & $45,78 \%$ \\
\hline 98 & Macapá & AP & $39,99 \%$ \\
\hline 99 & Porto Velho & RO & $32,89 \%$ \\
\hline 100 & Ananindeua & PA & $27,20 \%$ \\
\hline
\end{tabular}

Elaboração: TRINDADE, A. B. 2017.

Fonte: Instituto Trata Brasil. Ranking Saneamento 2014/2016.

\section{TABELAS 2 e 3. INDICADORES ÍNDICE DE ATENDIMENTO TOTAL (IN55) E URBANO (IN23) DE ÁGUA: DEZ ÚLTIMOS COLOCADOS - 2014/2016}

No gráfico 1, comparamos Ananindeua com a capital Belém no período 2006-2015, onde Ananindeua obteve média de 28,6\% indicando que praticamente não houve expansão do serviço para este município que apresenta os percentuais mais baixos, tanto para o abastecimento urbano quanto para o abastecimento total de água.

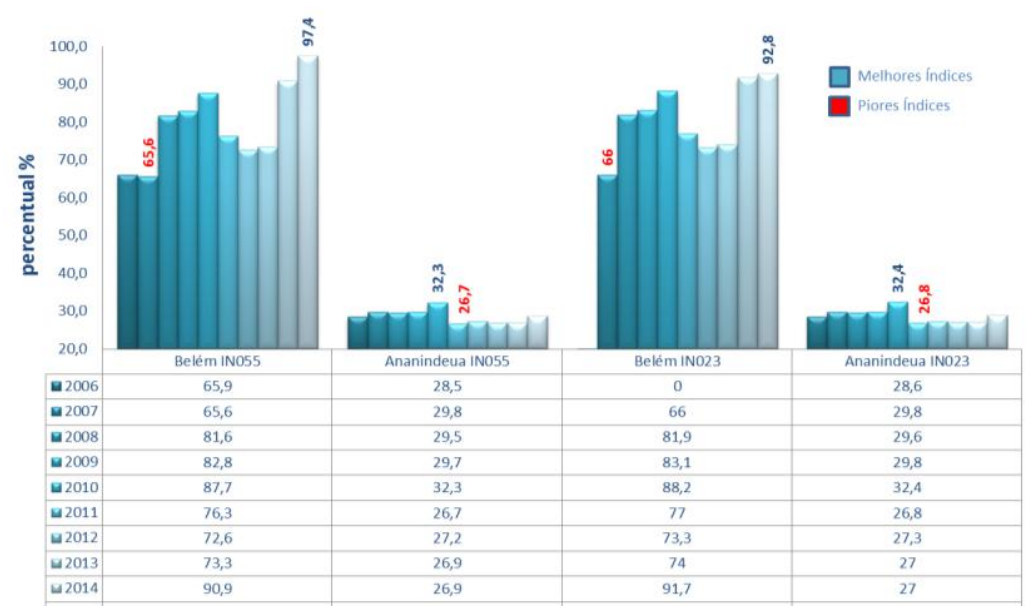

GRÁFICO1. ÍNDICE DE ATENDIMENTO TOTAL DE ÁGUA (IN055) E ÍNDICE DE ATENDIMENTO URBANO DE ÁGUA (INO23) MUNICÍPIOS DE BELÉM E ANANINDEUA 2006 -2015

\section{CONSIDERAÇÕES FINAIS}

Atentamos neste trabalho que a problemática nos serviços de abastecimento de água na Região Metropolitana de Belém, em especial no município de Ananindeua, merece atenção, pois foi possível evidenciar sérios problemas no que tange, ao sistema como um todo, principalmente o fornecimento de água tratada com ampla cobertura. O abastecimento de água, como observado nos dados, está concentrado áreas centrais da capital Belém onde está reunida a maioria dos equipamentos públicos, além de ser a 
primeira e mais antiga rede de abastecimento do estado. Isso demonstra a parca expansão do serviço, já que Ananindeua constituía o município de Belém até meados 1970 e a partir dai, no mesmo período do processo de expansão metropolitana, torna-se município independente, mas com carências nos equipamentos urbanos incluindo a cobertura adequada ao serviço de abastecimento de água.

REBOUÇAS, 2015 nos alerta que a falta de interesse em investimento para expansão da rede de tratamento de água se dá pela ingerência do recurso uma vez que o investimento por água subterrânea quando feita a partir de estudos que adequem a captação aos parâmetros de qualidade para consumo humano se apresenta em quantidade e qualidade melhor além de ter menor custo para distribuição. (p. 127). A falta de saneamento e cuidados dos efluentes que em geral são despejados sem tratamento nos nossos mananciais de abastecimento urbano, compromete a qualidade das águas e da saúde da população, além de aumentar os custos com tratamento e também os gastos com as perdas.

Diante disso vemos a preocupação de estudos que observam o abastecimento e gerenciamento das águas sob a ótica do estado, atendendo seus interesses que há tempos vêm colaborando com setores privados. Vemos também sua ingerência, um poder público que está omisso diante da realidade da população, que necessita de investimentos na expansão dos serviços seja por captação superficial ou subterrânea. Nas regiões metropolitanas brasileiras as águas subterrâneas poderiam abastecer as pequenas cidades, porém estão sendo utilizadas para abastecer: hotéis de luxo, hospitais, condomínios e principalmente indústria de bebidas, devido o valor monetário atribuído a esses usos.

A água é um bem de uso público, mas lhe é dado valor econômico. Nossas observações para a questão da "Gestão das Águas" se dá para justificar que não se trata apenas de conseguir mais água, e sim, de usar a que dispomos com inteligência. Pois, na região amazônica o recurso é abundante na sua forma in natura que desperta olhares de especulação, mas ainda carece de tratamento para que o amplo acesso de água potável seja garantido à população.

\section{Bibliografia}

ANA - Agencia Nacional de Água - Atlas Brasil de Abastecimento Urbano de Água http://atlas.ana.gov.br acesso em: 20/09/2014.

BECKER, Bertha. Inserção da Amazônia na geopolítica da água. In: ARAGÓN, Luis \& CLUSENERGODT, Miguel (org). Problemática do uso local e global da água da Amazônia. UNESCO/NAEA/UFPA. Belém, 2003.

BORDALO, C. A. L. O Desafio das Águas numa Metrópole Amazônida: Uma reflexão das políticas de proteção dos mananciais da região metropolitana de Belém-PA (1984 - 2004), Belém, 2006.

Distribuição Geográfica dos Serviços de Abastecimento de Água na Região Metropolitana de Belém - PA, Belém, 2014.

BORDALO, Carlos Alexandre Leão, Costa, Francisco Emerson Vale, GUEDES, Michel Pacheco., TRINDADE, Andreza Barbosa, SOUSA, Elivelton Santos., In: Christian Nunes da Silva, João Marcio Palheta da Silva; Gilberto Miranda da Rocha; Carlos Alexandre Leão Bordalo. (Org.). "O PARADOXO DA ÁGUA NA METRÓPOLE 
DAS ÁGUAS: O CASO DA REGIÃo METROPOLITANA DE BELÉM". In_Produção do Espaço e Territorialidade na Amazônia Paraense: Elementos para a análise geográfica. 1ed. Belém: GAPTA/UFPA, 2016, v. 1, p. 261-276.

COSANPA - Companhia de Saneamento do Estado do Pará - Plano Diretor do Sistema de Esgotamento Sanitário da Região Metropolitana de Belém - Relatório Técnico I Análise dos sistemas existentes de esgoto, água e drenagem urbana da RMB - José Almir Rodrigues Pereira, (coord.) - Universidade Federal do Pará. Grupo de Pesquisa Hidráulica e Saneamento, Companhia de Saneamento do Pará, Belém, 2007.

FENZL, Norbert et. al. A sustentabilidade do sistema de abastecimento de água de Belém - Belém: NUMA/UFPA, 2010.

GUEDES, M.P. A Gestão dos Recursos Hídricos e a Distribuição Geográfica dos Serviços de Abastecimento de Água na cidade de Belém - PA (2008-2015). Dissertação de mestrado. UFPA/PPGEO, 2016.

IBGE - Instituto Brasileiro de Geografia e Estatística. Pesquisa Nacional de Saneamento Básico 2008. Rio de Janeiro: IBGE, 2008.

Censo demográfico 2010. Rio de Janeiro: IBGE, 2010.

IPEA. Instituto de Pesquisa Econômica Aplicada. PROJETO: GOVERNANÇA METROPOLITANA NO BRASIL. Relatório 1.2. Caracterização e Quadros de Análise Comparativa da Governança Metropolitana no Brasil: Análise Comparativa das Funções Públicas de Interesse Comum. Instituto de Desenvolvimento Econômico, Social e Ambiental do Pará (IDESP), 2013.

LANNA, Antônio Eduardo. "Gestão dos recursos hídricos". (Org.) TUCCI, Carlos E. M. Hidrologia: Ciência e aplicação. Porto Alegre. 4". ed. Universidade ABRH, 2007, p.727-764.

Ministério das Cidades - Secretaria Nacional de Saneamento Ambiental - Sistema Nacional de Informações sobre Saneamento - SNIS. in Diagnóstico dos Serviços de Água e Esgotos - 2014. Brasília, Fevereiro, 2016.

Ministério do Planejamento, Orçamento e Gestão - Instituto Brasileiro de Geografia e Estatística - IBGE - Diretoria de Pesquisas - Coordenação de População e Indicadores Sociais. In 2008. Rio de Janeiro 2002.

PARÁ. Diretrizes de ordenamento territorial para a Região Metropolitana de Belém Secretaria de Estado de Desenvolvimento Urbano e Obras Públicas - SEDOP, 2006 - 270 p.

PEREIRA, José Almir Rodrigues (organizador). Plano diretor do sistema de abastecimento de água da Região Metropolitana de Belém. Síntese do plano diretor. 100 f. Belém: COSANPA; GPHS-UFPA, Set. 2006.

Plano Municipal de Saneamento básico de Abastecimento de Água e Esgotamento Sanitário De Belém - Pará volume I concepção técnica e proposições. - Secretaria Municipal de Saneamento - SESAN Belém, 2014

SETTI. Arnaldo Augusto. et al. Introdução ao gerenciamento de recursos hídricos. 328 p. Brasília: Agência Nacional de água, Agência Nacional de Energia Elétrica, 2001. 